\title{
PORTABILITY OF HUMAN CAPITAL AND IMMIGRANT OVEREDUCATION IN SPAIN
}

\author{
Esteve Sanromá \\ Institut d'Economia de Barcelona (IEB)-Universitat de Barcelona
}

Raúl Ramos

AQR-IREA-Universitat de Barcelona

Dept. Econometria, Estadística i Economia Espanyola

Avda. Diagonal 690, 08034 Barcelona (Spain)

Phone: +34+934024310

Fax $+34+934021824$

E-mail:rramos@ub.edu

\section{Hipólito Simón}

Universidad de Alicante, Instituto de Economía Internacional (IEI) \& IEB

\begin{abstract}
The literature on immigrant assimilation highlights the imperfect portability of the human capital acquired by immigrants in their country of origin, which accounts for their low levels of labor market integration upon arrival in the new country, as well as their initially wide earnings gap. Recent studies have examined this issue from the perspective of overeducation. This study analyzes the portability of immigrants' human capital into the Spanish job market according to their geographic origin. Spain’s immigrants originate from a highly varied range of countries, with origins as diverse as Latin America, the Maghreb and Eastern Europe. Here, the use of public microdata files from the Spanish Census permits us to identify up to six regions of immigrant origin comprising developed countries and developing economies, distinguishing, furthermore, different regions of origin on the basis of their language and level of development. The results obtained indicate differing degrees of transferability of human capital depending on geographic origin, with transferability being greater for immigrants from countries that are highly developed or which have a similar culture or language and lower for those from developing countries and with more distant cultures. As an immigrant's period of residence in Spain is prolonged, integration does take place but the pace is slow (between 7 and 9 years).
\end{abstract}

Key words: Immigration, overeducation, assimilation, labor market integration 


\section{Introduction and objectives}

The literature on immigrant assimilation reports the limited portability of human capital acquired by immigrants in their country of origin. The basic reason for the low valuation of immigrant human capital lies in an insufficient command of the language of the country of arrival, which conditions the productivity of the rest of the immigrant's skills. Additionally, the education system in the country of origin may suffer from shortcomings that translate into a lower quality of education acquired in origin by immigrants, while the work experience gained in origin might mean that the human capital acquired is specific to that country. As a result, the human capital imported by immigrants is comparatively less productive and, as such, less well paid than that of the native population, so that upon arrival in the host country a marked difference in earnings is observed between the two groups. However, as the immigrant's period of residence in the country is prolonged, the wage gap lessens - the phenomenon of assimilation - because the immigrant acquires knowledge and skills suited to the new job market.

The literature analyzing these issues empirically is wide ranging. Chiswick (1978), in examining assimilation for the first time, documented the lower marginal returns of immigrant human capital in the USA, noting as the reason the imperfect portability of human capital. Borjas $(1985,1995)$ confirmed these results while warning of the need to monitor the differing characteristics of immigrants from distinct cohorts. The results obtained for other economies with a tradition of immigration confirm the lower remuneration of immigrant human capital and the existence of the assimilation process, though the pace of this varies across countries (Chiswick and Miller, 1995, for Australia; Baker and Benjamin, 1994, for Canada; Bell, 1997, for the UK; Schmidt, 1992, and Constant and Massey, 2003, for Germany, and Longva and Raaum, 2003, for Norway). An important step forward in this line of work involved separating the education acquired by immigrants in their country of origin from their studies conducted in the country of destination. Thus, Shields and Wheatley Price (1998) estimate that non-white immigrants earn less for studies undertaken in origin compared with studies acquired in the UK. In analyzing immigration to Israel, Friedberg (2000) also finds that human capital imported from culturally distant countries receives a lower remuneration than that acquired in the country of destination, but that it is re-evaluated when complemented with the human capital acquired in Israel. Two additional findings from this literature are worth mentioning. On the one hand, the portability of 
human capital acquired in origin differs depending on the characteristics of the country the immigrant comes from. Thus, the greater the distance in terms of language, culture, and economic development, the less portable the human capital acquired abroad becomes and the greater the initial inequality in the job market in comparison with members of the native population (Shields and Wheatley Price, 1998 and Friedberg, 2000). On the other hand, the lower the portability and the greater the initial gap, the greater the speed of assimilation, as the incentives to invest in human capital in the country of arrival are stronger (Duleep and Regets, 1997).

Recent studies have dealt with this issue from the perspective of overeducation ${ }^{1}$. Overeducation is usually defined as the possession by workers of greater educational skills than their jobs require (Rumberger, 1981). The idea underpinning this new literature is that the imperfect portability of human capital acquired in origin forces immigrants to accept jobs requiring lower qualifications than those acquired in their country, making them formally overeducated workers ${ }^{2,3}$. The main outcomes of these recent studies can be summed up in three empirical regularities. Firstly, there is a greater incidence of overeducation among immigrants than there is among the native population. Secondly, the wage penalty associated with overeducation is also greater for immigrants. And thirdly, immigrant workers succeed in reducing the difference in overeducation with regard to the native population as their stay in the new country is prolonged, i.e. the phenomenon of integration takes place in overeducation, as occurred previously in terms of earnings.

As well as these common findings, the additional contributions of certain studies are worth highlighting. Chiswick and Miller (2007) find that the greater the work experience in the country of origin, the greater the probability of overeducation in the United States, which indicates low transferability not just of schooling but also of work experience acquired in origin. Their study is one of the few in which overeducation affects immigrants slightly less than it does the native population. However, considerable differences emerge according to the country of origin. In a later study, Chiswick and Miller (2008) claim that the educational mismatch explains almost two thirds of the differences in human capital returns of the native population and immigrants. Similar results are reported by Chiswick and Miller (2010) for the case of Australia, as well as for the United States and Canada. In the case of Australia, Green et al. (2007) conclude not only that recent immigrants have a greater rate of overeducation than the native-born population, but that the incidence is 
also higher among those from non-English-speaking countries, who show lower returns for overeducation. Kler (2006) confirms these same results for immigrants with tertiary studies. Using data from the United Kingdom, Lindley and Lenton (2006) find a higher percentage of overeducation not just among immigrants but also for non-white members of the native-born population. Using data for Denmark, Nielsen (2007) is able to separate home and host country studies and experience. On the one hand, she finds that overeducation affects immigrants with studies from abroad more than it does to natives and immigrants who have studied in Denmark. This result clearly shows that the core of the problem lies in the partial portability of human capital acquired in origin. On the other hand, immigrants with studies acquired abroad reduce their overeducation, as they increase their effective work experience in Denmark, and (though to a lesser degree) as their period of stay in the country increases without necessarily holding down a job. Immigrants who have only studied in Denmark, meanwhile, improve their work match through effective work experience. As for the returns of years of overeducation, this is lowest for immigrants with studies from abroad, followed by immigrants with Danish qualifications, and is highest for the native-born population. Using micro data from the 1996, 2001 and 2006 New Zealand censuses, Poot and Stillman (2010) show the need to control for origin heterogeneity when analyzing the pace of assimilation of immigrants in terms of overeducation. However, with data for Italy, Dell'Aringa and Pagani (2010) find that the "catch-up” by foreigners seems unachievable, even once they have adapted their skills to the host country's labor market. Comparing data from 25 countries, the OECD (2007) obtains similar results when disaggregating results for men and women, except in the case of Slovakia (women), Switzerland (men) and New Zealand (both genders), where overeducation affects the native population more. Aleksynska and Tritah (2013) obtain similar results using data from the European Social Survey for 22 European countries during the period 2002-2009.

In this context, examining the case of Spain is of particular interest for two reasons. First, the OECD (2006) reports that in the 21 member countries studied, the percentage of overeducated workers is higher among immigrants than it is among the native-born population, albeit with marked differences across these countries: for example, in the United States and Switzerland the gap is only an additional 2.5 percentage points, while in Greece and in Spain, overeducation is much higher among immigrants (30 and 19\%, respectively). Second, in contrast perhaps with many countries, immigration to Spain originates from a highly varied range of countries, with origins as diverse as Latin America, the Maghreb and Eastern Europe. 
Furthermore, immigration from Latin America is characterized by the sharing of both the Spanish language and culture, but the level of its development is clearly lower, and there are marked differences between the various countries on the continent.

As explained later with deeper detail, the research focuses on immigrants arriving to Spain between 1995 and 2001. As shown in figure 1, during this period, net immigrants increased at never seen rates. According to national official statistics, the stock of foreign-born population more than doubled between 1995 and 2001. Since 2002 tougher migration policies were adopted and, although the Spanish economic boom up to 2007 and the extraordinary regularization processes in 2005 and 2008 acted as very important pull factors, net entries progressively declined in relative terms. This decline is specially marked after the onset of the Great Depression ${ }^{4}$.

\section{FIGURE 1}

The objective of this article is to undertake a detailed analysis of immigrant integration from the perspective of the portability of human capital and overeducation, an aspect that has yet to be considered for Spain ${ }^{5}$ and one which has received relatively little coverage internationally. Furthermore, it takes the novel approach of analyzing the intensity of overeducation (measured as the number of "surplus" years of schooling) and not just its incidence (the probability of being overeducated), as has been the case in the literature to date. Finally, the study analyzes immigrants from both developed and developing economies, distinguishing, furthermore, between different regions of origin according to language and level of development.

The rest of the paper is organized as follows: First, the second section presents the dataset; Next, the third section describes the incidence and intensity of overeducation among the native population and among immigrants by area of origin. The fourth section studies the portability of human capital and immigrant integration using discrete choice models and regression models. Last, the article ends with a final section in which we present our main conclusions.

\section{Datasets and sample characteristics}


Both the Population Census and the Labor Force Survey (LFS) offer information at the individual level on the schooling and employment levels of Spaniards and foreigners, so overeducation of both groups can be calculated using both sources. In fact, in both cases, information on the immigrants' year of arrival is provided making it possible to study the portability of human capital and immigrant integration over time. However, sample size and representativeness are clearly greater in the Census than they are in the LFS. In fact, the use of the Census allows for differentiation by various areas of origin, a key aspect when studying differences in human capital portability according to geographic and cultural origin, but it also enables us to work with more than 200 different occupations (3-digit level of the Spanish Clasificación Nacional de Ocupaciones, CNO-1994), a key variable for the analysis of overeducation. For this reason, this study draws on the anonymous microdata sample file of the Spanish Population Census of 2001, produced by the National Institute of Statistics (INE) and representing five per cent of the total population ${ }^{6}$. From this information it is possible to identify the country of birth of individuals (the criterion used to identify them as immigrants), as well as the year of their arrival in Spain ${ }^{7,8}$. The study has employed observations corresponding to economically active individuals aged between 16 and 65. Moreover, only immigrants with a minimum age of 16 upon arrival in Spain were chosen so as to ensure that they had completed primary studies in their country of origin.

The information on the country of birth makes it possible to identify up to six regions of immigrant origin regions which are geographic but also cultural, economic and also related to race/ethnicity. Specifically, for the purposes of this study they are described as the developed economies, the Southern Cone of South America (Argentina, Chile and Uruguay), the rest of Latin America (with a majority of immigrants from Ecuador and Colombia), countries in Eastern Europe (with a predominance of Romanians and Bulgarians), the Maghreb (Morocco, Algeria and Tunisia) and the rest of the world, including Sub-Saharan Africa and Asian as the main groups ${ }^{9}$. In order to take into account differences in the level of development of origin countries, data on per capita Gross Domestic Product in constant 2005 US dollars for the year 2001 has been obtained from the Word Bank Development Indicators dataset. 
An additional difficulty in analyzing the situation in Spain is that it has not been possible to obtain longitudinal data that would essentially allow the changing make-up of immigrants and their characteristics to be monitored. This difficulty has been solved by taking as a sample only immigrants arriving in Spain after 1995, which brings several advantages. Firstly, this is a seven-year cohort, which is even shorter than the ten-yearly cross-section normally available when working with several censuses. Furthermore, this allows us to examine a relatively homogenous group of immigrants within each geographic area of origin. Finally, it covers a single phase of economic expansion in Spain, characterized by intense job creation ${ }^{10}$.

\section{Overeducation: incidence and intensity}

The literature has developed three procedures to measure educational mismatch: the objective method, the subjective method and the statistical method (mean or mode). The objective method involves comparing workers' level of education with the levels needed to perform the functions associated with their position, according to a panel of experts. The subjective method is based on surveys in which individuals self-classify themselves directly into one of the aforementioned categories, or on surveys enquiring about the nature of their job, which allows them to be classified indirectly. The statistical method based on the mean (Verdugo and Verdugo, 1989) considers that a person is overeducated (undereducated) if he/she have a level of education that is higher (lower) by more than one standard deviation than the mean level of education of the workers in that occupation. Nevertheless, Kiker et al. (1997) propose the use of the mode instead of the mean; so they consider a person who has a higher (lower) level of education than the mode for the job they perform to be overeducated (undereducated). It should be noted that Mendes de Oliveira et al. (2000) propose an improvement to the method based on the mode which consists of only including in the study those occupations for which the most common (mode) level of education of the workers represents at least $60 \%$ of all the workers who perform that job. Usually, the choice of one of those methods tends to be determined by the availability of statistical information rather than by any specific theoretical motivation. In this case, the information made available by the Population Census facilitates the calculation of statistical measures (mean and mode) of educational mismatch. Given that the statistical method tends to underestimate the educational mismatch, particularly in its version based on the mean (Groot and Maassen van den Brink, 2000), and taking into account that the Census provides highly disaggregated information about occupations 
at a 3-digit level, we have chosen to use the corrected mode criterion proposed by Mendes de Oliveira et al. (2000).

Table 1 shows the results relating to age, number of schooling years and the educational mismatch of Spaniards and immigrants. In line with the aforementioned international evidence, the incidence of overeducation is greater among immigrants than it is among Spaniards ${ }^{11}$. In particular, immigrants register a higher incidence of overeducation than Spaniards with a difference of nearly 10 percentage points. The results in Table 1 also show that there are sizeable differences in the percentage of overeducated workers according to geographic origin. Thus, whereas immigrants from developed countries record a lower incidence of overeducation (very close to that observed for Spaniards) at the other extreme immigrants from developing countries with similar schooling levels experience significantly higher rates of overeducation. The exceptions are immigrants from the Maghreb and the rest of the world where overeducation rates are lower due to poorer human capital endowments. The last columns of table 1 show the incidence of overeducation by schooling levels in order to correct for educational composition effects. A similar picture to the one obtained when looking at raw data emerges: the higher incidence of overeducation in some geographic areas seems to be related to differences to the incomplete nature of the transferability of immigrants' human capital that could be explained by an insufficient command of Spanish, cultural distances or by other factors such as race discrimination.

\section{TABLE 1}

As we can see from table 2, immigrants in the Spanish labor market not only suffer from a greater incidence of overeducation, but they also show a greater intensity of overeducation, measured in the number of "surplus” years of study Indeed, the percentage of immigrants with intense overeducation is clearly higher than that of the native population. Thus, $12 \%$ of immigrants with secondary studies have five or more years of surplus studies, a figure which falls to less than $3 \%$ for the native-born population. The values for individuals with tertiary studies provide a similar picture: $86 \%$ of immigrants exhibit an intense overeducation as opposed to $69 \%$ for Spaniards. By calculating the intensity of overeducation separately for immigrants from developed and developing countries, we find that overeducation is more intense for those 
from developing countries when comparing the same levels of education. Thus, immigrants with at least five years of overeducation make up $89 \%$ of postgraduate-qualified immigrants arriving from developing countries, but $67 \%$ of those coming from developed countries (69\% for Spaniards). For graduates, the figures are 12 and 7\%, respectively (2\% for Spaniards). This not only confirms the previous results regarding the limited portability of human capital acquired through the education system in the country of origin, it also emphasizes that the difficulty can be even greater for university qualifications, particularly when acquired in countries with a lower level of development. What would seem to be contributing to this outcome is that some qualifications are not fully recognized and so employers express a degree of mistrust in the quality of some degree courses, particularly when there is an excess supply of graduates from Spanish universities ${ }^{12}$.

\section{TABLE 2}

In short, the results obtained reveal that overeducation tends to punish immigrants more in both its incidence and intensity, in all probability due to the incomplete portability of human capital. ${ }^{13}$ Moreover, this problem is worse for the more highly qualified immigrants from countries with lower levels of development and a more distant language, culture and different race/ethnicity.

\section{Determinants of overeducation. Portability of studies and integration}

To identify the determinants of overeducation, an ordered logit model was estimated for an endogenous variable, with three categories ordered as follows: being unemployed, being overeducated and being suitably

educated. ${ }^{14}$ Specifically, it was supposed that the probability of individual $i$ being unemployed, overeducated and suitably educated would be explained by a series of factors relating to different individual characteristics (gender, studies and age $^{15}$ ) and family characteristics (married and number of children), as well as the fact of being an immigrant and the number of years spent in Spain. Territorial controls were also included (regional dummy variables ${ }^{16}$ and variables relating to the size of the town of residence), as they were considered to affect both the probability of finding a job and the type of match. From the maximum likelihood estimation of the equations system formed by the ordered logit, it is then possible to obtain estimations of the influence 
of each of these factors on the probability of going from one of the three categories to the one immediately above.

It should be stressed that by considering the possibility that individuals might remain unemployed and not accept a job for which they are overeducated, this controls the possible endogeneity between work and overeducation that might affect immigrants to a greater degree than it does Spaniards, as immigrants do not enjoy the family networks or social protection that would allow them to prolong the time they spent looking for a job in keeping with their level of training. The proposed model is estimated jointly for Spaniards and immigrants, providing details in some specifications as to the immigrants’ geographic region of origin.

The outcomes of the various models (Table 3) coincide in estimating a greater probability of males improving their position in the job market (going from unemployed to overeducated to suitably educated) than that of women doing so. The number of schooling years has a positive effect on the probability of improvement. Its relatively weak effect would appear to be related to the fact that, although higher education makes it easier to leave unemployment, it also increases the probability of overeducation. Age, which should to some extent capture the effect of accumulating experience, is also positively related to job improvement. As for family variables, marriage and children are linked to a greater probability of improvement, which coincides with the wage increase normally associated with this status.

\section{TABLE 3}

The results from model 1 indicate that upon arrival in Spain immigrants have a much lower probability of improving their situation in the job market compared to Spaniards with similar characteristics. This clearly indicates that the same number of schooling years and the same approximate potential experience - albeit both acquired in the country of origin - place immigrants at a clear disadvantage with respect to the nativeborn population, who have acquired their human capital in Spain. Human capital acquired abroad is therefore limited in its transferability to the Spanish job market. Finally, the number of years spent living in Spain, during which time immigrants can perfect their command of the language, establish contacts, accumulate learning, develop skills and acquire experience, all adapted to the Spanish job market, increases the 
probability of their improving their situation in the job market, which can be interpreted as a clear sign of integration. The country of birth GDP per capita also increases the probability of improving immigrants' situation in the labor market. As additional controls, the specification also includes dummies for those occupations with the highest presence of immigrants. In particular, these occupations, mostly related to personal services sectors, ${ }^{17}$ account for the $46 \%$ of immigrants' total employment and for the $21 \%$ of natives’ employment.

Model 2 replaces the "immigrant" dummy variable with two variables reflecting two general regions of origin: developed and developing economies; model 3 replaces it with six variables reflecting the specific regions of origin defined above. The aim of these two models is to investigate whether differences exist between these areas. The results from models 2 and 3 show that such differences do indeed exist. Upon arrival, the greatest probabilities of improvement (albeit always lower than those for a Spaniard) are recorded by immigrants from developed economies, although the difference in model 2 is not statistically significant from those from developing economies. When the regions of origin are further disaggregated in model 3, we find clear differences between immigrants from the Southern Cone and the rest of the immigrants, specifically, those from the Maghreb and the rest of the world who clearly are in the worst position. However, rather than revealing degrees of portability of immigrant human capital, this result is more likely conditioned by the restrictions of the financial liquidity of these immigrants upon arrival in Spain, and by their lower wage reserve in comparison with those held by other groups, which allows them to leave unemployment quickly, even though it may be via the informal economy. It is worth mentioning that once regions of origin are disaggregated in models 2 and 3, the country of birth GDP per capita is no longer statistically significant at the usual levels probably due to the presence of multicollinearity.

Model 3 also allows for the pace of integration to differ depending on origin. It can be seen that each additional year spent residing in Spain increases the probability of job improvement to a greatest extent for immigrants from the Southern Cone, Latin America, Eastern Europe, Western Europe and the Maghreb, whereas integration is not observed for immigrants from the rest of the world, since the effect is not statistically significant at the usual levels. This result suggests the possibility that immigrants from this area remain permanently trapped in lower-paid jobs, regardless of their levels of education. 
In the analysis carried out so far, overeducation has been a unique status, with no consideration of its intensity. In other words, the probability of leaving unemployment or overeducation has been studied by considering that the only possibility for improvement lies in a change of status. However, overeducation can have differing degrees of intensity and, as such, reducing the intensity of overeducation could be a form of job improvement, i.e. of making progress in their integration path. The following analysis therefore deals with the intensity of overeducation measured as the number of years of overeducation.

With this objective, the analysis of the portability of human capital and the process of integration was widened to consider the intensity of overeducation. In particular, a linear regression model was estimated for the number of years of overeducation comparing the actual years of schooling with those required for the occupation. The exogenous variables include individual characteristics and family variables, and, where appropriate, the fact of being an immigrant and the number of years spent in Spain, together with the same occupational dummies shown in table 3 . However, before proceeding to estimate this model, we should first consider the fact that, for unemployed immigrants, it is impossible to determine what their educational mismatch is. Analyzing the factors that determine the educational mismatch without considering that there is a group of individuals not in employment could lead to inaccurate results - the well-known problem of selection bias. To solve this issue, the model was estimated by applying a two-stage procedure as proposed by Heckman (1979). The first stage of the Heckman procedure is to analyze the probability of having a job or otherwise based on various individual characteristics together with family variables (civil status and number of children) and private vehicle availability, whereas the second stage is to analyze the years of overeducation including the Heckman's lambda (obtained in the first stage as the inverse of the Mills ratio) as an additional explanatory variable. This variable includes the effects of all uncontrolled characteristics relating to the fact that there are individuals not in employment. The model was estimated jointly for Spaniards and immigrants, drawing a distinction in some specifications for an immigrant's area of origin.

Table 4 shows the results obtained by estimating the regression model described in the earlier paragraphs. Firstly, they confirm that schooling increases the intensity of overeducation. This is a typical result in both the international and Spanish literature, though normally it refers to the probability of being overeducated. 
Secondly, age seems to have a negative effect on the intensity of overeducation. Although not a rigorous contrast, this result seems to confirm certain substitutability between education and other forms of human capital, as proposed by the theory of human capital. Thirdly, men experience a more intense overeducation. This result differs from the more usual outcomes reported in the literature, whereby the gender variable has no effect on the probability of being overeducated (Groot and Maasen van den Brink, 2000). Regarding occupational dummies, the obtained results show that agricultural workers experience the higher overeducation intensity followed by shop assistants, waiters, cleaners and cooks.

\section{TABLE 4}

But the key variables in this analysis refer to the fact of being an immigrant, and the evidence obtained in model 1 shows that upon arrival immigrants have an overeducation that is 0.65 years more intense than that of Spaniards, which again suggests the incomplete portability of human capital acquired abroad. Knowledge acquired while living in Spain now also reduces overeducation, specifically at a rate of 0.108 years of overeducation for each year of residency, requiring 7 years to eliminate the mismatch.

Models 2 and 3 show that, upon arrival in Spain, immigrants from the Maghreb, Eastern Europe, Latin America and the rest of the world have three or more years of overeducation than that presented by Spaniards, and as such it is their origins which give their human capital lower portability. The human capital of immigrants from the Southern Cone has greater, but still limited, portability, whereas foreigners from developed economies bring human capital that is most suited to the job market, as shown by the fact that their overeducation is, upon arrival, almost the same as that of Spaniards (a difference of only 0.3 years). It can thus be concluded once again that human capital from countries with a similar or higher level of development is almost completely equivalent to Spanish human capital, and human capital from the same cultural and language spheres is to a very large degree transferable. However, human capital acquired in countries with a lower level of economic and technological development, and with a distant culture and language, has a very imperfect portability. 
Finally, the results also show the pace of integration in overeducation intensity. As can be seen in model 3, the pace of integration ranges from 0.03 to 0.21 fewer years of overeducation for each year of residence and with no statistical evidence of integration from immigrants from the Southern Cone and the rest of the world (although, in the former case, their initial positions are the least unfavorable). Immigrants from Eastern Europe, the Maghreb and Latin America record the most intense pace of integration, requiring between 7 and 9 years of residence to reduce overeducation.

\section{Conclusions}

This study has analyzed the portability of human capital of immigrants (from six different regions of origin) and the latter's subsequent integration into the Spanish job market. The key variable in this study was overeducation, with both its incidence and intensity (an aspect hitherto not considered in the literature) coming under review.

Our descriptive analysis shows that overeducation affects immigrants more than it does the native population, but that significant differences present themselves depending on the region of origin of the immigrants, with a lower portability of human capital being detected among those from countries with a lower level of development and with a distant language and culture. Even after controlling for educational composition effects, immigrants also present a more intense overeducation, particularly those originating from developing countries.

Our econometric analysis, with discrete choice and regression models, shows that the portability of human capital is imperfect, given that as well as observable characteristics, immigrants present a more intense overeducation (above all those from developing countries) than that presented by the native population. The situation is comparatively better for immigrants from developed countries. We are, therefore, able to confirm that human capital from countries with equal or greater economic and technological development is almost perfectly transferable to the Spanish job market, and that human capital from countries with the same cultural and language background is reasonably portable. By contrast, human capital acquired in geographic regions with lower development and with a distant culture and language has a very imperfect transferability. 
Finally, we confirm that immigrants living in Spain can accumulate knowledge and experience that are perfectly adapted to the local job market, thus facilitating an integration process that reduces the intensity of overeducation. The pace of integration however is relatively slow for immigrants from developing countries, between 7 and 9 years of living in Spain being necessary to eliminate their educational mismatch. There is thus a high risk that immigrants from certain regions experience difficulties to improve their labor market outcomes, regardless of their levels of education.

To conclude, it must be noted that previous results on immigrants overeducation are in line with the characteristics of the Spanish labour market, where immigrants tend to be concentrated in the secondary segment of the labor market, characterized by low-paid, unstable and unskilled jobs, and where this part of the labour market is comparative large from and international perspective (Simón, Sanromá and Ramos, 2011), with a presence of temporary jobs and of low-skilled jobs significantly higher than in other advanced countries (Kogan, 2006).

\section{Endnotes}

${ }^{1}$ See Piracha and Vadean (2013); Dustman and Glitz (2011) and Leuven and Oosterbeek (2011).

${ }^{2}$ Possible differences in quality of the different national education systems limit any comparison of the native population and immigrants. Nevertheless, many other factors (including an incomplete command of the language, qualifications not being recognized and studies adapted to another system of production) reduce the expected productivity of hiring immigrants, leading them to accept lower-paid jobs.

${ }^{3}$ An alternative explanation could be related to the duality in the Spanish labor market. Labor market segmentation theories split the labor market up into a primary segment containing the good jobs and a secondary segment with bad, unstable jobs (Doeringer and Piore, 1971). While in the primary market, and more particularly in internal markets (within firms), overeducation usually exists at the entry-level and diminishes through promotion, in the secondary market overeducation tends to be more persistent phenomenon due to the assumed dead-end character of the jobs in this labor market segment (Dekker et al, 
2002). The results by Alcobendas and Rodriguez-Planas (2009) show that immigrant's occupational assimilation in Spain is only observed for some low-skilled groups of immigrants. This occurs because native low-skilled workers are more likely to work in the secondary segment, which is of easier access to immigrants, facilitating the occupational convergence between immigrants and their native counterparts. However, their results do not fully reject the human capital theory.

${ }^{4}$ Spain is a developed country that has experienced recent immigration on a massive scale. Consequently, since the middle of the nineties and up to the onset of the economic crisis, Spain experienced a process of sustained economic growth which attracted large immigrant inflows. Spanish economic growth was focused in low-productivity activities and, as a result, mostly created jobs in unskilled occupations (the sectors with higher employment growth were building, real estate, domestic services, hospitality and personal services and a substantial portion of new hires was on fixed-term contracts). As a consequence, immigrants concentrated in labour-intensive activities with low levels of qualification, complementing the jobs held by natives (Amuedo and De la Rica, 2011). After the Great Recession, immigrants' situation in the Spanish labour market has deteriorated sharply and, inter alia, unemployment has affected them considerably.

${ }^{5}$ With the exception of Fernández and Ortega (2008), who estimate probit models with LFS microdata for the probability of being overeducated. However, they do not consider the intensity of overeducation and they work at a lower level of geographic detail for the origin of immigrants. In addition, to calculate overeducation they apply a statistical method based on the average, a procedure criticized in the literature (Hartog, 2000).

${ }^{6}$ Specifically, we use the public microdata files distributed by the INE on May 5th 2011 and available at http://www.ine.es/prodyser/micro_censopv.htm.

${ }^{7}$ In the context of this study, one limitation of the Census is its lack of information regarding immigrants' command of Spanish, which makes it impossible to analyze in detail its influence on the portability of human capital and its subsequent labor market integration (see Blázquez and Rendón, 2012). The analysis details immigrants’ regions of origin to proxy their knowledge of the Spanish language.

${ }^{8}$ Foreign born individuals with Spanish nationality at birth have been excluded from the analysis.

${ }^{9}$ Developed economies are the EU-15 plus Norway, Switzerland, Iceland, Cyprus, Malta, the small European principalities, USA, Canada, Israel, Japan, Australia and New Zealand. The majority of 
immigrants in this group are from the UK, Germany and Italy. The Rest of America is defined as countries on the American continent south of the USA, except for Argentina, Chile and Uruguay, a region referred to here as the Southern Cone. Included also in Latin America is Equatorial Guinea, the only country in Africa where Spanish is the official language. Despite the fact that a large number of the Eastern European countries currently form part of the European Union, it was decided to draw this distinction due to the notable differences with Spain in terms of development, especially Romania and Bulgaria, the countries with the greatest number of immigrants. It is worth highlighting that the last category, the rest of the world, including Sub-Saharan Africa and Asian immigrants, is a very heterogeneous group. It would have been interesting to separate immigrants from these two different realities but the small size of the Census sample prevented us to proceed that way.

${ }^{10}$ As a robustness check, the empirical analysis has been replicated considering all immigrants instead of those arriving from 1995 to 2001. Overall, results are very similar to those presented in the article. This evidence is available from the authors on request.

${ }^{11}$ We only focus on overeducation as the literature has clearly found that undereducated workers do not experience negative consequences in terms of wages due to their job-occupation mismatch (see, for instance, Leuven and Oosterbeck, 2011).

${ }^{12}$ Using the Spanish Immigrants National Survey (Encuesta Nacional de Inmigrantes) Simon, Sanroma and Ramos (2011) observe that only around 5\% of immigrants hold degrees that were recognised in Spain and that the recognition of foreign education is a very influential determinant of the occupational mobility of immigrants between their home countries and Spain, given that it provides access to a significantly higher occupational status in the Spanish labor market. Unfortunately, data from the Spanish Population Census do not include information on the recognition of foreign education in Spain and, consequently, its influence on immigrant overeducation cannot be examined.

${ }^{13}$ It must be also considered that some form of discrimination toward immigrants could also be present in hiring decisions. There are several theories that explain the existence of discrimination in the labor market against collectives as immigrants based on nationality or ethnicity: the taste for discrimination model (Becker, 1957), the statistical theory of discrimination (Phelps, 1972) and the crowding-out hypothesis 
(Bergmann, 1974). Evidence documenting discrimination in the labour market against immigrants can be found in Zegers de Beijl (2000) and Siniver (2011) and, specifically for Spain, in Sole and Parella (2003).

${ }^{14}$ Following a referee's suggestion, we have also specified and estimated an ordered logit adding undereducation as an additional category. The obtained results are very similar to the ones shown here. Full details are available from the authors on request.

${ }^{15}$ The decision to include age rather than potential experience was related to potential measurement errors in the former due to different institutional and social situations in each of the immigrants' countries of origin. ${ }^{16}$ The level of regional disaggregation used in the analysis corresponds to the 52 "provincias" in which the Spanish territory is divided according to the NUTS 3 of the European Commission territorial classification. More details can be obtained at http://epp.eurostat.ec.europa.eu/portal/page/portal/nuts_nomenclature/introduction ${ }^{17}$ Domestic cleaners and helpers (911); Agricultural, forestry and fishery labourers (941); Labourers in construction (960); Waiters (502); Building frame and related trades workers (711); Shop sales assistants (533); Cleaners and helpers in offices, hotels and other establishments (912); Cooks (501). ISCO 3 digitcodes in parenthesis. 


\section{References}

Alcobendas, M.A., Rodríguez-Planas, N. (2009). Immigrants' Assimilation Process in a Segmented Labor Market, IZA Discussion Paper No. 4394.

Aleksynska, M. \& Tritah, A. (2013). The Occupation-Education Mismatch of Immigrant Workers in Europe: Context and Policies. Economics of Education Review. vol. 36, pp. 229-244.

Amuedo, C.; De la Rica, S. (2011). Complements or substitutes? Task Specialization by Gender and Nativity in Spain. Labour Economics, 18(5), pp. 697-707.

Becker, G.S. (1957). The Economics of Discrimination , ed. University Chicago Press.

Bergmann, B. (1974). Occupational Segregation, Wages and Profits whem Employers Discriminate by Race or Sex. Eastern Economic Journal, pp. 103-110.

Bell, B. (1997). The Performance of Immigrants in the United Kingdom: Evidence from the GHS. Economic Journal, vol. 107, n. 441, pp. 333-344.

Blázquez, M. \& Rendón, S. (2012). Overeducation in Multilingual Economies: Evidence from Catalonia. International Migration, forthcoming.

Borjas, G. (1985). Assimilation, Changes in Cohort Quality, and the Earnings of Immigrants. Journal of Labor Economics, vol. 3, n. 4, pp. 463-489.

Borjas, G. (1995). Assimilation and Changes in Cohort Quality Revisited: What Happened to Immigrant Earnings in the 1980s?. Journal of Labor Economics, vol. 13, n. 21, pp. 201-245. 
Chiswick, B. (1978). The Effect of Americanization on the Earnings of Foreign-born Men. Journal of Political Economy, vol. 86, n. 5, pp. 897-921.

Chiswick, B. \& Miller, P. (1995). The endogeneity between language and earnings: an international analysis. Journal of Labor Economics, vol. 13, n. 2, pp. 246-288.

Chiswick, B. \& Miller, P. (2007). The International Transferability of Immigrants' Human Capital Skills. IZA Discussion paper n. 2670, March 2007, 27 p.

Chiswick, B. \& Miller, P. (2008). Why is the payoff to schooling smaller for immigrants?. Labour Economics, vol. 15, pp. 1317-1340.

Chiswick, B. \& Miller, P. (2010). The Effects of Educational-Occupational Mismatch on Immigrant Earnings in Australia, with International Comparisons. International Migration Review, vol. 44, n. 4, pp. 869-898.

Constant, A. \& Massey, D. (2003). Self-selection, earnings, and out-migration: A longitudinal study of immigrants to Germany. Journal of Population Economics, vol. 16, pp. 631-653.

Dekker, R., de Grip, A., \& Heijke, H. (2002). The effects of training and overeducation on career mobility in a segmented labor market. International Journal of Manpower, vol. 23, pp. 106-125.

Dell'Aringa. C. \& Pagani, L. (2010). Labor Market Assimilation and Over Education: The Case of Immigrant Workers in Italy. Quaderni dell'Istituto di Economia dell'Impresa e del Lavoro, 57.

Doeringer, P. B. \& Piore, M. J. (1971). Internal Labor Markets and Manpower Adjustment, D.C. Heath and Company, New York. 
Duleep, H. \& Regets, M. (1997). The Decline in Immigrant Entry Earnings: Less Transferable Skills or Lower Ability?. The Quarterly Review of Economics and Finance, vol. 37, Special Issue, pp. 189-208.

Dustman, C. \& Glitz, A. (2011). Migration and Education. in Handbook of the Economics of Education, vol. 4, pp. 327-439.

Fernández, C. \& Ortega, C. (2008). Labor market assimilation of immigrants in Spain: employment at the expense of bad job-matches?. Spanish Economic Review, vol. 10, n. 2, pp. 83-107.

Friedberg, R. (2000). You Can’t Take It with You? Immigrant Assimilation and the Portability of Human Capital. Journal of Labor Economics, vol. 18, n. 2, pp. 221-251.

Green, C., Kler, P. \& Leeves, G. (2007). Immigrant overeducation: Evidence from recent arrivals to Australia. Economics of Education Review 26, pp. 420-432.

Groot, W. \& Maassen Van den Brink, H. (2000). Overeducation in the Labor Market: A Meta-Analysis. Economics of Education Review vol. 19, pp. 149-158.

Hartog, J. (2000). Over-education and earnings: where are we, where should we go?. Economics of Education Review vol. 19, pp. 131-147.

Kiker, B.F., Santos, M.C. \& Mendes de Oliveira, M. (1997). Overeducation and Undereducation: Evidence for Portugal. Economics of Education Review, vol. 16 (2), pp. 111-125.

Kler, P. (2006). Overeducation among tertiary educated immigrants to Australia: A longitudinal study. Labor Economics Research Group, University of Queensland, Discussion Paper n. 9, January 2006, 39 p.

Kogan, I. (2006). Labor Markets and Economic Incorporation among Recent Immigrants in Europe, Social Forces, vol. 85, pp. 697-721. 
Lindley, J. \& Lenton, P. (2006). The Overeducation of UK Immigrants: Evidence from the Labor Force Survey. Sheffield Economic Research Paper Series n. 2006001, 20 p.

Leuven, E. \& Oosterbeck, H, (2011). Overeducation and Mismatch in the Labor Market in Handbook of the Economics of Education, vol. 4, pp. 283-326.

Longva, P. \& Raaum, O. (2003). Earnings assimilation of immigrants in Norway - A reappraisal. Journal of Population Economics, vol. 16, pp. 177-193.

Mendes de Oliveira, M., Santos, M.C. \& Kiker, B.F. (2000). The Role of Human Capital and Technological Change in Overeducation. Economics of Education Review, vol. 19 (2), pp. 199-206.

Nielsen, Ch. P. (2007). Immigrant Overeducation: Evidence from Denmark. World Bank Policy Research Working Paper 4234, may 2007, 54 p.

OECD (2006). International Migration Outlook, Annual Report 2006. OECD, Paris.

OECD (2007). International Migration Outlook, Annual Report 2007. OECD, Paris.

Phelps, E. (1972). The Statistical Theory of Racism and Sexism. American Economic Review, 62(4), pp. 659-661.

Piracha, M. \& Vadean, F. (2013). Migrant Educational Mismatch and the Labour Market. in International Handbook on The Economics of Migration, Edward Elgar, Chapter 9.

Poot, J. \& Stillman, S. (2010). The Importance of Heterogeneity When Examining Immigrant EducationOccupation Mismatch: Evidence from New Zealand. IZA DP 5211.

Rumberger, R. (1981). Overeducation in the US Labor Market. Praeger, New York. 
Schmidt, C. (1992). Country of origin differences in the earnings of German immigrants. Discussion Paper 92-29, University of Munich.

Siniver, E. (2011). Testing for Statistical Discrimination: The Case of Immigrant Physicians in Israel. Labour, Vol. 25, Issue 2, pp. 155-166.

Simon, H., Sanroma, E. \& Ramos, R. (2011). Occupational Mobility of Immigrants in a Low Skilled Economy: The Spanish Case. IZA DP No. 5581.

Sole, C. \& Parella, S. (2003). The labour market and racial discrimination in Spain. Journal of Ethnic and Migration Studies, Volume 29, Issue 1, pp. 121-140.

Shields, M. \& Wheatley Price, S. (1998), The earnings of male immigrants in England: evidence from the quarterly LFS, Applied Economics, vol. 30, pp. 1157-1168.

Verdugo, R. \& Verdugo, N. (1989). The impact of surplus schooling on earnings. Journal of Human Resources, vol. 24 (4), pp. 629-643.

Zegers de Beijl, R. (2000). Documenting Discrimination against Migrant Workers in the Labour Market, ed. International Labour Office, Geneva. 


\section{Figures and tables}

Figure 1. Year-on-year variation in the number of foreign-born population in Spain

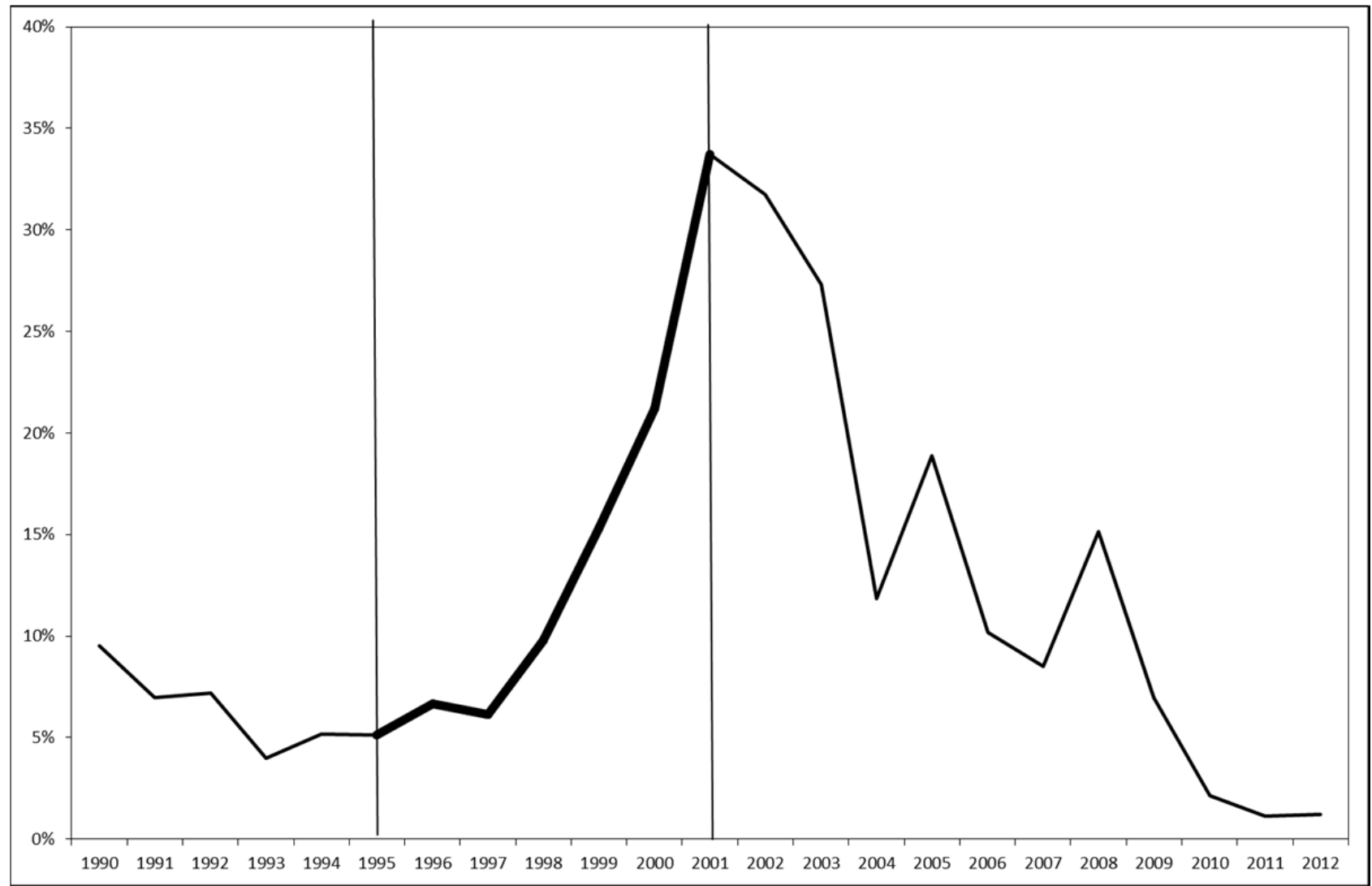

Source: Spanish National Institute of Statistics 
Table 1. Incidence of overeducation.

\begin{tabular}{|c|c|c|c|c|c|c|}
\hline & \multirow{2}{*}{ Age } & \multirow{2}{*}{ Schooling years } & \multicolumn{4}{|c|}{$\%$ Overeducated } \\
\hline & & & All & Primary studies & Secondary studies & Tertiary studies \\
\hline Spaniards & 37.61 & 9.38 & $27.23 \%$ & $3.42 \%$ & $65.09 \%$ & $40.38 \%$ \\
\hline Immigrants & 32.68 & 8.62 & $37.04 \%$ & $12.14 \%$ & $77.77 \%$ & $62.55 \%$ \\
\hline Developed economies & 36.19 & 11.35 & $28.46 \%$ & $5.68 \%$ & $43.32 \%$ & $35.27 \%$ \\
\hline Developing economies & 32.23 & 8.27 & $38.15 \%$ & $12.57 \%$ & $83.33 \%$ & $73.08 \%$ \\
\hline Eastern Europe & 32.68 & 8.68 & $43.44 \%$ & $13.37 \%$ & $87.43 \%$ & $83.97 \%$ \\
\hline Southern Cone & 33.46 & 10.59 & $43.05 \%$ & $6.34 \%$ & $70.99 \%$ & $59.88 \%$ \\
\hline Latin America & 32.38 & 9.05 & $41.11 \%$ & $11.02 \%$ & $84.57 \%$ & $73.18 \%$ \\
\hline Maghreb & 30.96 & 5.39 & $28.25 \%$ & $18.09 \%$ & $81.72 \%$ & $69.88 \%$ \\
\hline Rest of the World & 32.07 & 6.89 & $27.15 \%$ & $8.52 \%$ & $81.23 \%$ & $72.94 \%$ \\
\hline
\end{tabular}

Table 2. Intensity of overeducation by levels of studies. (\% of overeducated workers)

\begin{tabular}{llcccc}
\hline & & $1-2$ years & $3-4$ years & 5 or more years & Total \\
\hline Spaniards & Secondary studies & $28.89 \%$ & $68.84 \%$ & $2.27 \%$ & $100.00 \%$ \\
& Tertiary studies & $7.79 \%$ & $23.41 \%$ & $68.80 \%$ & $100.00 \%$ \\
\hline Immigrants & Secondary studies & $13.98 \%$ & $74.05 \%$ & $11.97 \%$ & $100.00 \%$ \\
& Tertiary studies & $2.23 \%$ & $11.86 \%$ & $85.91 \%$ & $100.00 \%$ \\
\hline Developed & Secondary studies & $21.76 \%$ & $70.98 \%$ & $7.25 \%$ & $100.00 \%$ \\
economies & Tertiary studies & $5.11 \%$ & $28.13 \%$ & $66.76 \%$ & $100.00 \%$ \\
\hline Developing & Secondary studies & $13.32 \%$ & $74.31 \%$ & $12.37 \%$ & $100.00 \%$ \\
economies & Tertiary studies & $1.69 \%$ & $8.84 \%$ & $89.47 \%$ & $100.00 \%$ \\
\hline Eastern Europe & Secondary studies & $20.02 \%$ & $64.37 \%$ & $15.60 \%$ & $100.00 \%$ \\
Southern Cone & Tertiary studies & $1.08 \%$ & $4.30 \%$ & $94.62 \%$ & $100.00 \%$ \\
\multirow{2}{*}{ Latin America } & Secondary studies & $12.37 \%$ & $75.00 \%$ & $12.63 \%$ & $100.00 \%$ \\
\multirow{2}{*}{ Maghreb } & Tertiary studies & $3.00 \%$ & $18.00 \%$ & $79.00 \%$ & $100.00 \%$ \\
Rest of & Secondary studies & $11.76 \%$ & $77.34 \%$ & $10.90 \%$ & $100.00 \%$ \\
the World & Tertiary studies & $1.59 \%$ & $8.22 \%$ & $90.19 \%$ & $100.00 \%$ \\
\hline & Secondary studies & $13.75 \%$ & $69.54 \%$ & $16.71 \%$ & $100.00 \%$ \\
& Tertiary studies & $2.44 \%$ & $8.94 \%$ & $88.62 \%$ & $100.00 \%$ \\
& Secondary studies & $9.85 \%$ & $78.79 \%$ & $11.36 \%$ & $100.00 \%$ \\
& Tertiary studies & $1.61 \%$ & $12.90 \%$ & $85.48 \%$ & $100.00 \%$ \\
\hline
\end{tabular}


Table 3. Determinants of the probability of being unemployed, overeducated or properly educated

\begin{tabular}{|c|c|c|c|}
\hline Odds-ratio & (1) & (2) & (3) \\
\hline Male & $1.583 * * *$ & $1.582 * * *$ & $1.582 * * *$ \\
\hline Schooling years & $1.061^{* * *}$ & $1.061^{* * *}$ & $1.061 * * *$ \\
\hline Age & $1.020^{* * *}$ & $1.020 * * *$ & $1.020^{* * *}$ \\
\hline Married & $1.085^{* * *}$ & $1.085^{* * *}$ & $1.086^{* * *}$ \\
\hline Number of children & $1.106 * * *$ & $1.106^{* * *}$ & $1.106 * * *$ \\
\hline Immigrant & $0.476^{* * *}$ & & \\
\hline Developed economies & & $0.576^{* * *}$ & $0.557 * * *$ \\
\hline Developing economies & & $0.313 * * *$ & \\
\hline Eastern Europe & & & $0.375^{* * *}$ \\
\hline Southern Cone & & & $0.291 * * *$ \\
\hline Latin America & & & $0.376 * * *$ \\
\hline Maghreb & & & $0.567 * *$ \\
\hline Rest of world & & & $0.649 *$ \\
\hline Years of residence & $1.081^{* * *}$ & & \\
\hline x Developed economies & & $1.093 * * *$ & $1.093 * * *$ \\
\hline x Developing economies & & $1.068^{* * *}$ & \\
\hline x Eastern Europe & & & $1.076^{* * *}$ \\
\hline x Southern Cone & & & $1.148 * * *$ \\
\hline x Latin America & & & $1.075^{* * *}$ \\
\hline x Maghreb & & & 1.019 \\
\hline $\mathrm{x}$ Rest of the world & & & 0.960 \\
\hline Country of Birth GDPpc (log) & $1.062^{* *}$ & $0.878^{* *}$ & 0.977 \\
\hline Domestic cleaners and helpers & $4.739 * * *$ & $4.784 * * *$ & $4.847 * * *$ \\
\hline Agricultural, forestry and fishery labourers & $2.355^{* * *}$ & $2.347 * * *$ & $2.323 * * *$ \\
\hline Labourers in construction & $5.378 * * *$ & $5.390 * * *$ & $5.401 * * *$ \\
\hline Waiters & $2.968 * * *$ & $2.972 * * *$ & $2.976 * * *$ \\
\hline Building frame and related trades workers & $5.687 * * *$ & $5.693 * * *$ & $5.703 * * *$ \\
\hline Shop sales assistants & $2.531 * * *$ & $2.532 * * *$ & $2.533 * * *$ \\
\hline Cleaners and helpers in offices, hotels and other establishments & $4.916^{* * *}$ & $4.927 * * *$ & $4.935^{* * *}$ \\
\hline Cooks & $3.096 * * *$ & $3.094 * * *$ & $3.096 * * *$ \\
\hline Pseudo R2 & 0.0405 & 0.041 & 0.041 \\
\hline AIC & 1352216 & 1352128 & 1352061 \\
\hline Observations & 675,957 & 675,957 & 675,957 \\
\hline
\end{tabular}


Table 4. Determinants of the intensity of overeducation (number of years)

\begin{tabular}{|c|c|c|c|}
\hline Coefficients & (1) & (2) & (3) \\
\hline Male & $0.655 * * *$ & $0.656 * * *$ & $0.662 * * *$ \\
\hline Schooling years & $0.723 * * *$ & $0.724 * * *$ & $0.731 * * *$ \\
\hline Age & $-0.0140 * * *$ & $-0.0141 * * *$ & $-0.0149 * * *$ \\
\hline Immigrant & $0.651^{* * *}$ & & \\
\hline Developed economies & & $0.327 * * *$ & $0.287 * *$ \\
\hline Developing economies & & $0.767^{*}$ & \\
\hline Eastern Europe & & & $1.509 * * *$ \\
\hline Southern Cone & & & 0.199 \\
\hline Latin America & & & $1.031 * * *$ \\
\hline Maghreb & & & $1.888 * * *$ \\
\hline Rest of the world & & & 0.806 \\
\hline Years of residence & $-0.108 * * *$ & & \\
\hline x Developed economies & & $-0.0339 *$ & $-0.0356^{*}$ \\
\hline x Developing economies & & $-0.116^{* * *}$ & \\
\hline x Eastern Europe & & & $-0.207 * * *$ \\
\hline x Southern Cone & & & 0.042 \\
\hline $\mathrm{x}$ Latin America & & & $-0.139 * * *$ \\
\hline x Maghreb & & & $-0.139 * * *$ \\
\hline $\mathrm{x}$ Rest of the world & & & -0.105 \\
\hline Country of Birth GDPpc (logs) & $-0.679 * * *$ & $-0.640 * * *$ & $-0.502 * * *$ \\
\hline Domestic cleaners and helpers & 0.0502 & 0.0477 & 0.0824 \\
\hline Agricultural, forestry and fishery labourers & $2.794 * * *$ & $2.794 * * *$ & $2.749 * * *$ \\
\hline Labourers in construction & -0.123 & -0.123 & -0.127 \\
\hline Waiters & $0.329 * * *$ & $0.329 * * *$ & $0.337 * * *$ \\
\hline Building frame and related trades workers & -0.141 & -0.140 & -0.143 \\
\hline Shop sales assistants & $0.520 * * *$ & $0.520 * * *$ & $0.522 * * *$ \\
\hline Cleaners and helpers in offices, hotels and other est. & $0.273 * * *$ & $0.272 * * *$ & $0.277 * * *$ \\
\hline Cooks & $0.192 * *$ & $0.193 * *$ & $0.202 * * *$ \\
\hline Heckman’s Lambda & $1.369 * * *$ & $1.373 * * *$ & $1.437 * * *$ \\
\hline $\mathrm{R}^{2}$ & 0.536 & 0.536 & 0.537 \\
\hline Observations & 214,333 & 214,333 & 214,333 \\
\hline
\end{tabular}

OLS estimates. Robust cluster estimated standard errors by country of birth. ${ }^{*} \mathrm{p}<.10$; ${ }^{* *} \mathrm{p}<.05 ;{ }^{* * *} \mathrm{p}<0.01$. 


\section{Appendix 1. Descriptive statistics}

\begin{tabular}{|c|c|c|c|c|c|c|c|c|c|}
\hline & Spaniards & Immigrants & $\begin{array}{l}\text { Developed } \\
\text { Economies }\end{array}$ & $\begin{array}{l}\text { Developing } \\
\text { Economies }\end{array}$ & $\begin{array}{l}\text { Eastern } \\
\text { Europe }\end{array}$ & $\begin{array}{c}\text { Southern } \\
\text { Cone }\end{array}$ & Latin America & Maghreb & $\begin{array}{c}\text { Rest of the } \\
\text { World }\end{array}$ \\
\hline Full sample & 877,495 & 29,449 & 3,355 & 26,094 & 4,026 & 1,857 & 13,349 & 4,599 & 2,261 \\
\hline Employed & $85.96 \%$ & $82.06 \%$ & $82.50 \%$ & $82.00 \%$ & $82.79 \%$ & $75.93 \%$ & $82.82 \%$ & $81.34 \%$ & $82.09 \%$ \\
\hline Overeducated & $27.24 \%$ & $37.04 \%$ & $28.47 \%$ & $38.15 \%$ & $43.44 \%$ & $43.05 \%$ & $41.11 \%$ & $28.25 \%$ & $27.16 \%$ \\
\hline Years of overeducation & 3.82 & 5.21 & 4.45 & 5.28 & 5.46 & 4.95 & 5.22 & 5.51 & 5.28 \\
\hline Male & $59.86 \%$ & $59.13 \%$ & $62.27 \%$ & $58.72 \%$ & $59.84 \%$ & $54.71 \%$ & $48.79 \%$ & $81.87 \%$ & $71.65 \%$ \\
\hline Schooling years & 9.38 & 8.62 & 11.35 & 8.27 & 8.68 & 10.59 & 9.05 & 5.39 & 6.89 \\
\hline Age & 37.61 & 32.68 & 36.20 & 32.23 & 32.68 & 33.46 & 32.38 & 30.97 & 32.07 \\
\hline Married & $77.59 \%$ & $40.63 \%$ & $57.23 \%$ & $38.49 \%$ & $44.26 \%$ & $58.27 \%$ & $40.79 \%$ & $24.31 \%$ & $27.24 \%$ \\
\hline Number of children & 0.88 & 0.40 & 0.43 & 0.39 & 0.31 & 0.61 & 0.44 & 0.30 & 0.23 \\
\hline Years of residence & --- & 2.95 & 3.64 & 2.86 & 2.66 & 2.70 & 2.69 & 3.33 & 3.38 \\
\hline Private vehicle availability & $78.46 \%$ & $39.96 \%$ & $72.55 \%$ & $35.77 \%$ & $38.85 \%$ & $48.25 \%$ & $29.25 \%$ & $44.75 \%$ & $40.29 \%$ \\
\hline
\end{tabular}

